\title{
SOBRE A HISTORICIDADE DE TEXTOS ${ }^{1}$
}

\author{
Johannes Kabatek ${ }^{2}$ \\ Tradução: José da Silva Simões (DO-USP) ${ }^{3}$
}

1. As seguintes linhas nascem da minha profunda convicção da importância continuada da lingüística histórica e de que, na minha opinião, um número considerável das atuais questões centrais da teoria da linguagem só serão resolvidas se elas resistirem, de certa forma, a uma revisão desde a perspectiva histórica - bem ao contrário, portanto, do que afirmam erroneamente algumas tendências atuais anunciando a morte da lingüística histórica. ${ }^{4} \mathrm{Um}$ segundo motivo é o fato de que eu ultimamente tenho trabalhado no campo das assim chamadas tradições discursivas ${ }^{5}$, confrontando-me continuamente com o problema de que o status teórico-lingüístico das mesmas na verdade não está claro e parece necessário ser revisado mais uma vez.

2. Apesar dos inúmeros trabalhos que nos últimos anos giram em torno do tema das tradições discursivas (TD), parece-me que ainda não há um consenso sobre onde verdadeiramente as TD devam ser alocadas na teoria da linguagem. ${ }^{6}$ Nesse sentido, em diversos trabalhos, tentouse definir o lugar das TD com relação à diferenciação de Eugenio Coseriu entre três níveis da linguagem ${ }^{7}$, o que, no entanto, não tem sido feito da forma idêntica por todos os autores.

\footnotetext{
${ }^{1}$ N.T.: O presente texto é a versão modificada de um capítulo do livro "Die bolognesische Renaissance" (Kabatek, 2004) a ser publicado brevemente em Tübingen (Alemanha).

N.T.: O texto foi traduzido a partir do alemão, com a anuência e a preciosa revisão e a necessária correção do Prof. Dr. Johannes Kabatek do departamento de Romanística da Universidade de Tübingen, com quem mantive diálogo por correio eletrônico durante a tradução do mesmo. Sem a sua colaboração, não seria possível manterme fiel ao verdadeiro espírito deste texto. Também as notas de rodapé, quando em alemão no original, foram traduzidas e, à exceção óbvia da citação de Hegel, não houve a preocupação de buscar a tradução das citações de Eugene Coseriu, que possivelmente podem ser encontradas em português.

${ }^{2}$ Prof. Dr. Johannes Kabatek do Departamento de Romanística da Universidade de Tübingen (Alemanha).

${ }^{3}$ Doutorando da área de filologia e Língua Portuguesa - FFLCH - USP.

${ }^{4}$ N.T.: a tradução da citação foi colhida em Hegel, Georg Wilhelm Friedrich (1990). Fenomenología do espírito. Parte II. Tradução de Paulo Meneses com a colaboração de José Nogueira Machado, SJ. Petrópolis. Editora Vozes, p.48 [508].

${ }^{4}$ Tal como no número especial 31-1 da revista La Corónica, no qual foi estudada a questão da suposta morte da Lingüística Histórica; cf. a minha argumentação contrária em Kabatek 2003.

${ }^{5}$ Kabatek (2001) e Kabatek (2004). Sobre o conceito de tradições discursivas cf. Koch (1997), Aschenberg (2003).

${ }^{6}$ As considerações seguintes referem-se, em linhas gerais, a um capítulo em Kabatek (2004).

7 "A fala é uma atividade universal genericamente humana, que é realizada individualmente em determinadas situações respectivamente por falantes individuais como representantes de comunidades lingüísticas com tradições comunitárias do saber-falar.” Coseriu (1988:70)

Os três diferentes níveis são caracterizados por Coseriu da seguinte forma:

"1. O falar representa aspectos universais genericamente humanos; ela o 'falar em geral'. Todos os seres humanos adultos e normais falam. Inclusive o silêncio está em uma relação direta com o falar, pois silenciar significa 'parar de falar' '(ainda) não falar' [...].

2. Cada falar é falar uma determinada língua em particular. Na verdade, fala-se sempre em uma determinada tradição histórica [...].

3. O falar é sempre individual, e notadamente em duas perspectivas: por um lado é sempre realizado por um indivíduo; não é um ato em coro. Cada um fala por si, e também no diálogo o papel do falante e do ouvinte é tomado em intercâmbio. Por outro lado, é individual na medida em que acontece respectivamente em uma
} 
A tentativa mais difundida nos últimos anos no âmbito da romanística enquadra as TD no nível histórico, que com isso se duplica: ${ }^{8}$

No nível histórico é preciso distinguir entre dois campos. De um lado, é preciso falar de tradições discursivas, (gêneros, tendências estilísticas, formas conversacionais) [...]. De outro lado naturalmente interessa, sobretudo, cada uma das línguas históricas particulares." (Koch/Oesterreicher 1994, 589)

Dessa forma, a fala seria uma atividade universal cuja prática deveria passar por uma sorte de filtro de tradição duplo: a intenção do ato comunicativo precisaria sempre ser alinhada adequadamente à organização lingüística, onde os signos são escolhidos seguindo uma ordem adequada às regras sintáticas de uma língua particular (de acordo com um sistema e com a realização comum de uma determinada norma). Concomitantemente, seria necessário que ela se referisse a uma ordem textual que atualizasse determinadas tradições discursivas, o que pode ser ilustrado de forma esquematizada como segue:

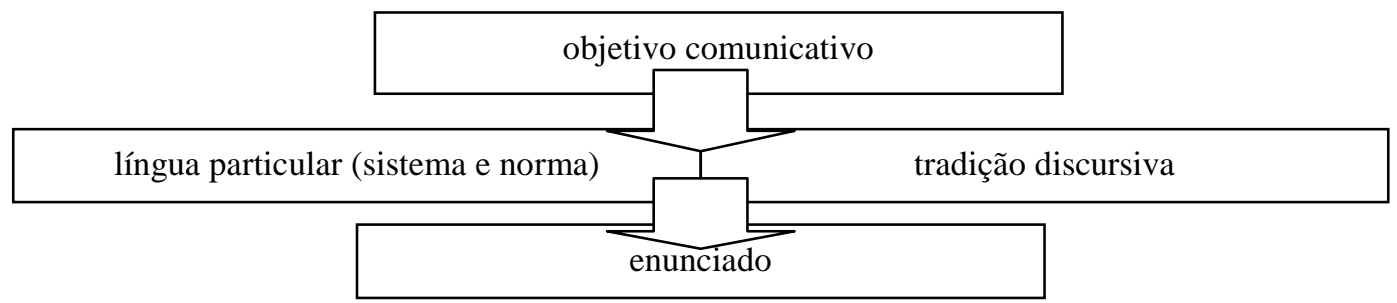

Em oposição a esta visão, outros autores tentam alocar as tradições textuais no plano individual, outros ainda postulam que o adequado seria a duplicação de todos os três níveis, o que significa dizer que, por um lado, seriam vistos como níveis do lingüístico, e por outro lado, como níveis do textual.

3. Pensamos, pois, que será preciso resolver em diferentes sentidos a questão do status das manifestações lingüísticas com respeito à relação entre TD e língua, para chegar a uma clareza sobre a posição das TD na teoria da linguagem. Para isso, parece, em primeiro lugar, necessário definir de maneira mais precisa o próprio conceito de historicidade. É útil, nesse contexto, lembrar um debate no qual se procurava definir o que realmente se entende por historicidade na teoria da linguagem de Eugenio Coseriu, um debate anterior à noção das TD e no qual e se tratava dos atos de fala. Por ocasião de uma discussão sobre a questão acerca da historicidade dos atos de fala no ano de 1979, Eugenio Coseriu mesmo chamava a atenção de que o pressuposto básico para a correta situação do problema se dá através do esclarecimento do que se entende realmente por historicidade. Nessa ocasião, Coseriu diferencia três conceitos distintos de historicidade: ${ }^{9}$

- historicidade lingüística strictu senso (historicidade da língua dada),

determinada situação única. Para a denominação desse ato individual em uma determinada situação proponho do francês discours - o termo 'discurso'. Em alemão diz-se para esse nível também 'texto' [Text]; com isso é preciso, no entanto, levar em conta que se trata aqui em primeiro lugar da atividade em si e não do seu produto.” (ibidem, 70-71)

${ }^{8}$ Cf. também Koch (1997: 45ss).

${ }^{9}$ In: Schlieben-Lange/Weydt (1979), cf. também Coseriu (1978). 
- historicidade como tradição (i.e., recorrência) de determinados textos ou de determinadas formações textuais,

- historicidade genérica no sentido de uma "pertença à história".

Falemos, em primeiro lugar, acerca da historicidade da língua. Esta ocupa aqui um lugar especial, uma vez que não se trata da historicidade dos objetos, senão sobre a do próprio homem como um ser histórico. A língua como língua particular é a história de uma comunidade internalizada no indivíduo. Ela é a forma primária do ser comunitário e o pressuposto para outras tradições culturais, ${ }^{10}$ "pois tudo que ali é criado deve ser denominado por meio da linguagem e é transmitido como conhecimento por meio da linguagem". ${ }^{11}$ Por meio de uma língua particular, o indivíduo se torna um ser social, ${ }^{12}$ é por meio dela que a existência do homem se torna realidade, já que é uma existência compartilhada com uma comunidade, como diz Hegel $^{13}$

Com efeito, a linguagem é o ser-aí do puro $\mathrm{Si}$, como $\mathrm{Si}$; pela linguagem entra na existência a singularidade para si essente da consciência-de-si, de forma que ela é para os outros. ${ }^{14}$

Essa historicidade primária, que é condicionada por meio da alteridade, ou seja, pela "potencialidade inerente de ser transferida a outros", 15 é própria apenas à língua como língua particular, uma técnica dada historicamente. Ela condiciona a existência [So-Sein] do homem, o homem não pode retroceder à linguagem, pois, na realidade, é por meio dela que ele existe como homem. ${ }^{16} \mathrm{O}$ indivíduo falante incorpora na aquisição da linguagem uma língua particular, ele a recria dentro de si como técnica aberta, a qual lhe permite a ação lingüística criativa.

O segundo tipo de historicidade, ao contrário, refere-se a todos as manifestações culturais repetíveis, incluindo as lingüísticas. Trata-se aqui das tradições de uma comunidade, da recorrência na criação de objetos culturais, da possibilidade de se referir a fatos culturais anteriores, evocados em fatos novos por conta de semelhança funcional ou formal ou por parcial harmonia. Trata-se aqui daqueles objetos culturais disponíveis em uma comunidade para a repetição, a qual sempre inclui a mudança em duas direções possíveis: ampliando o

\footnotetext{
${ }^{10}$ A linguagem é o pressuposto de todas as outras formas de organização humano-social: “A afirmação de que as tarefas sociais sejam resolvidas por meios lingüísticos, não se deve entender no sentido de que as tarefas constituam-se de forma extra- ou pré-lingüística. A línguagem, diga-se, está aí desde o início. As tarefas sociais só puderam ser instauradas e desenvolvidas desta maneira, sob a condição de que os integrantes da sociedade conversam entre si. A organização social também sempre se constitui por meios lingüísticos." (Schlieben-Lange, 1983, 138). Cf. também Gadamer 1965, 268ss.

${ }^{11}$ Coseriu 1978, 121.

${ }^{12}$ Cf. Aristoles, Política, I.

${ }^{13}{ }^{13}$ N.T.: a tradução da citação foi colhida em Hegel, Georg Wilhelm Friedrich (1990). Fenomenología do espírito. Parte II. Tradução de Paulo Meneses com a colaboração de José Nogueira Machado, SJ. Petrópolis. Editora Vozes, p.48 [508].

${ }^{14}$ Phänomelogie, VI, B, Ia. Coseriu reforçou repetidamente que o conceito de língua por ele desenvolvido (sobretudo em Sincronia, diacronia e história) remete, por um lado, no que tange a questão da historicidade e a origem da língua particular, a Aristoteles, mas também, por outro lado, quando fala da radicalidade com a que dá ênfase sobre a historicidade, ainda mais a Hegel.

${ }^{15}$ Coseriu $(1978,121)$. O conceito de alteridade nessa forma em particular Coseriu assume de Antonio Pagliaro, cf. Schlieben-Lange (1998).

${ }^{16} \mathrm{O}$ que de forma alguma significa que o indivíduo estaria "preso" por uma língua em uma visão do mundo determinada, no entanto, ao contrário, ela possibilita-lhe o acesso a todas as línguas - o que, contudo, pressupõe sempre o domínio de uma língua primária.
} 
modelo anterior ou particularizando-o. ${ }^{17}$ No que se refere à linguagem como objeto fala-se aqui de textos que estabelecem uma relação de tradição com outros textos. Essa pode dar-se, por um lado, pela repetição de uma determinada finalidade textual ou de um determinado conteúdo, e por outro lado, pela repetição de certos traços formais. A recorrência de formas textuais compreende uma escala contínua a partir de marcações de tradição mínimas - algo como uma determinada denominação textual ou uma determinada fórmula em um texto ainda não fixado - passando por uma organização formal contínua até chegar a uma completa fixidez do texto. Um romance, por exemplo, por conta dessa denominação, estabelece uma relação com uma tradição literária particular, mas também pode distanciar-se dessa mesma tradição em quase todos os elementos. ${ }^{18}$ Em razão das fórmulas de início e de desfecho, uma carta pode demonstrar fixidez e ao mesmo tempo ser livre nas restantes partes do texto, enquanto que uma fórmula de juramento, pronunciada sempre usando as mesmas palavras textuais, apresenta o grau máximo de fixidez. Na escala de fixidez, pelo menos outras duas escalas (e provavelmente mais) ${ }^{19}$ podem ser diferenciadas, de um lado o grau de fixidez de partes formalmente determináveis (p.e. "título", "sinopse", "introdução" etc.) e, de outro lado, o grau de fixidez da realização lingüística particular das mesmas partes. Quer dizer que um texto pode ter um vínculo de tradição dentro de uma comunidade textual, determinável à base de critérios textuais-formais, e por outro lado, também com uma determinada comunidade lingüística. Estes dois tipos de vínculos não são idênticos e no máximo podem corresponderse casualmente. ${ }^{20}$ Dessa forma, uma fórmula introdutória como Era uma vez situa um texto dentro de uma comunidade cultural como conto infantil e dispõe-no em relação com outros textos, que começam com Es war einmal, Once upon a time, Il était une fois ou Érase una vez; ao mesmo tempo, ela estabelece uma relação com uma outra forma lingüística particular desse tipo textual, o conto de fadas em língua portuguesa. ${ }^{21}$

$\mathrm{O}$ terceiro conceito de historicidade, por fim, refere-se a acontecimentos individuais, irrepetíveis e únicos, ${ }^{22}$ no sentido do texto como indivíduo, ou seja, como cada texto em particular. ${ }^{23}$ Aqui, trata-se do fato de que cada texto realizado é situável como acontecimento em algum lugar historicamente. Essa forma de "historicidade" poderia, na verdade, ser desprezada na questão da tradição lingüística e textual, mas ela está, porém, no centro da

\footnotetext{
${ }^{17}$ Schlieben-Lange (1983:138).

${ }^{18}$ Sobre a história do conceito de romance ver o clássico texto de Voelker (1886).

19 Também seria possivel estabelecer, além das duas escalas aqui descritas, uma escala de semelhança ou diferença do conteúdo, uma escala de semelhança ou diferença das constelações pragmáticas, e talvez ainda mais.

20 "As tradições textuais estão, se assim quisermos, ancoradas em coletividades textuais, em instituiçãoes, p.e., ou em grupos literários. Que oportunamente as comunidades textuais coincidam com as comunidades lingüísticas é um fenômeno secundário.” Schlieben-Lange (1983:139).

${ }^{21}$ Wilhelm (2001:469).

${ }^{22}$ Sobre essa historicidade refere-se Foucault, quando ele fala da historicidade do discurso em contraposição à linguagem: "le discours, à la différence peut-être de la langue, est essentiellement historique", uma vez que ele não é composto de "éléments disponibles", senão de "événements réels et successifs", que não se podem analisar fora de sua particularidade histórica (Foucault 1969, 260; veja-se também de la Higuera 1999,21ss). A língua é aqui, por esse motivo, a-histórica, porque ela é uma técnica intrínseca, não de forma temporal, para a criação de fenômenos lingüísticos particulares.

${ }^{23}$ Essa "historicidade" do ato único é, com efeito, aquela que Foucault vê como verdadeiramente histórica, pois situa-se na história, enquanto que Coseriu nega essa historicidade e diz, "que a criação por si mesma não demonstra nenhum desenvolvimento e com isso não pode ter nenhuma história em sentido próprio: A Ilias, a Divina Commedia não se desenvolvem, elas permanecem idênticas a si mesmas eternamente, e por isso também só podem achar seu lugar em uma história do homem eterna e atemporal." (Coseriu, 1978,118). Bem como Schlieben-Lange (1983:138): "Um texto em particular não tem uma história, ele é o produto respectivamente individual da ação comunicativa."
} 
pesquisa filológica tradicional, e, sobretudo, porque características funcionais ou formais de um texto individual servem como exemplo ou modelo para outros textos e um determinado texto é, por esse motivo, uma parte da tradição - e pode ser visto, por isso mesmo, também dentro do segundo aspecto de historicidade.

4. Com efeito, pode-se perguntar agora, se é verdadeiramente preciso manter a diferenciação proposta entre uma historicidade primária, da língua, e uma historicidade secundária das tradições textuais. A partir daí, poder-se-ia argumentar que uma fala que não esteja relacionada com determinadas tradições de textos não pode existir de forma alguma. Mas aqui não se trata da questão se, visto de fora, cada texto, no imenso arquivo de textos já realizados pelas pessoas, já foi realizado alguma vez ou se um texto pode ser vinculado a uma tradição. Na realidade, sempre é assim, mesmo em casos de relação tradicional negativa: também um texto que rompe com todas as tradições precedentes é relacionável com elas, ainda que seja precisamente pela ruptura. Muito mais do que isso, trata-se aqui da questão se no ato de falar o vínculo com determinadas tradições textuais é dado primariamente e interiorizado no indivíduo da mesma maneira que o vínculo com uma língua. Esta questão não pode ser respondida completamente aqui, mas ela pode ser lançada em duas direções. Primeiramente, existe uma diferença fundamental entre a tradição internalizada da língua particular, cuja particularidade mais chamativa é precisamente que para o sujeito falante ela esteja dissociada da tradição, e ela liberte o indivíduo da tradição já que, como técnica, como sistema funcional, é um instrumento de liberdade; é um mecanismo de fala que possibilita a criação livre de enunciados que não são necessariamente repetições de quaisquer realizações anteriormente feitas. Em segundo lugar, existe uma diferença qualitativa entre o fato de os falantes falarem uma língua particular e o fato de se eles servirem das tradições textuais. Um texto (inclusive um texto lingüisticamente misto) é sempre inerente a uma língua determinada; ele não pode ser "um pouco" ou "muito" português, alemão etc. O vínculo com tradições textuais, ao contrário, é gradual: existem formas textuais tradicionais muito definidas, como, por exemplo, o soneto, mas também formas muito pouco fixadas, como uma conversação descompromissada em um bar, a qual parece extremamente mais aberta e muito menos vinculada a uma tradição determinada. ${ }^{24}$

Um outro argumento contra a precedência da língua poderia ser observado, por exemplo, no fato de que freqüentemente na tradição medieval das línguas europeias, mas também em outras situações históricas, encontram-se certos textos lingüisticamente mistos com relativa estabilidade na forma textual. Parece ser que, nestes casos, a finalidade da mensagem e a forma textual são primárias, e a escolha da língua é secundária. Trata-se aqui, no entanto, de casos particulares da comunicação em situações de contato lingüístico, nos quais a finalidade dos textos consiste precisamente na transferência de uma determinada forma textual de uma língua para outra.

5. Até aqui apenas falou-se da historicidade das línguas em particular, das formas textuais e de textos como fenômenos universais, mas não de atos de fala. Isso reside no fato de que, como fenômenos universais, os atos de fala aqui foram conscientemente deixados de lado, pois o universal até inclui o histórico, mas na verdade é a-histórico. ${ }^{25}$ Contra essa

\footnotetext{
${ }^{24}$ A análise da conversação em parte demonstrou como, contrário ao que se pensava, também conversações livres são bastante regimentadas. A questão da definitude de tradição de todas as formas textuais não pode ser respondida de forma exaustiva aqui; e parece-me que também na pesquisa relativa a análise de conversação ela não foi respondida de forma definitiva. Aqui se trata, em primeira linha, de assinalar a gradualidade dos vínculos com a tradição textual.

${ }^{25}$ A discutida questão sobre a universalidade dos atos de fala (Schlieben-Lange 1979,67ss. e 83ss.) deve aqui ser evitada pela inversão. Como atos de fala, são considerados aqui somente aqueles atos que são universais. Naturalmente os atos universais estão sempre ligados a formas históricas. Um outro problema atinge a
} 
interpretação poder-se-ia argumentar que pode sim haver atos de fala que são tão históricos como uma língua determinada. Mas se em uma determinada língua existem técnicas para os atos de fala universais, então essas técnicas pertencem com certeza à historicidade do primeiro nível, a qual é precisamente a historicidade dessa língua em si: se em alemão uma ato de fala "pergunta" pode estar estar vinculado a uma determinada técnica, nesse caso, p.e., em certos casos com a inversão sintática, então isto não é uma técnica acessória, da qual faz uso o alemão, mas ela é uma técnica ancorada na língua alemã, que pertence à essência [SoSein] do alemão e com isso também ao próprio ser dos falantes dessa língua. Na historicidade vista nesse sentido, o sujeito e o objeto não podem ser separados. Quando eu falo alemão, então eu já estou nessa língua; eu não posso primeiro falar "universalmente" e depois, em um segundo passo, fazer uso do alemão. Assim eu também não posso pensar primeiro em fazer uma pergunta em alemão e só depois, em um segundo passo, imaginar, se faço isso com uma determinada técnica do alemão. Ao contrário, eu preciso fazê-lo com uma técnica dessa língua. Por isso, onde há técnicas lingüísticas para atos de fala em uma língua, a historicidade dos atos de fala coincide com a historicidade da língua mesma e nenhuma historicidade de atos de fala além da historicidade da língua precisa ser assumida. Mas quando os atos de fala em uma comunidade não são históricos no sentido de "pertencente à língua", eles só podem ser históricos no sentido do segundo nível, ou seja, tradicionais e acessórios. Ou seja, na realização desses atos, os falantes vinculam-se a determinadas tradições. ${ }^{26}$ Essas tradições ou são formalmente definíveis, a saber, quando para a expressão de um determinado ato de fala em uma comunidade é comum uma determinada forma textual, ou elas ainda são definidas de maneira mais precisa, quando um determinado ato de fala é expresso através de um determinado texto particular, uma fórmula por exemplo.

6. Ainda é necessário insistir aqui que deixar de lado os atos de fala na interpretação da historicidade lingüística e textual não nega nem a sua existência nem mesmo a sua historicidade. Diz-se apenas que os atos de fala não têm uma historicidade própria dissociável das outras historicidades. Mas eles podem ser transmitidos historicamente tanto através da historicidade primária da língua como através da historicidade secundária das tradições discursivas. E ainda mais: eles podem até ser transmitidos em ações simbólicas não lingüísticas, ${ }^{27}$ e justamente nisso reside uma grande liberdade que possibilita grandes diferenças em relação à ancoragem de determinados atos em distintas comunidades: um ato como "prometer" pode, segundo cada tradição, ser simbolizado por uma ação não-verbal, ele pode ser realizado por uma repetição não modificada de uma determinado texto (uma fórmula), ele pode requerer uma determinada forma textual ou até mesmo estar ancorado diretamente no sistema lingüístico. A negação duma historicidade própria dos atos de fala não conduz, portanto, a uma perda, mas a uma ampliação das possibilidades, de como determinados atos podem vir a ser históricos.

\footnotetext{
historicidade dos atos de fala que estão ligados a instituições. Segundo Habermas (1971, 113) estes "não pertecem a universais pragmáticos”. Sua história é indissociável da história das respectivas instituições. Mas exatamente por este motivo também não se trata de atos universais, mas de elementos de tradição cultural em particular, que podem se manifestar tanto em línguas particulares como em formas textuais ou textos.

${ }^{26}$ O caráter "acessório" das tradições textuais mostra-se através do fato de que a historicidade de formas textuais é comparável a outras formas culturais, algo como as tradições da arte, da música, do esporte, da religião etc. (Koch, 1997: 61), que estão vinculadas a comunidades culturais e não a comunidades lingüísticas. O caráter essencial da língua, ao contrário, mostra-se também em seu caráter "pre-comutado": somente através da língua as outras tradições são acessíveis; a língua é o sistema de signos primário que define o sujeito e que é necessário para a assimilação de todos os outros sistemas de signos e tradições.

${ }^{27}$ Austin (1962:121).
} 
7. O objetivo das linhas anteriores era de duas espécies: em primeiro lugar, o reforço à singularidade e à precedência da historicidade lingüística, que não pode ser situada no mesmo nível de outras historicidades ou tradições. No entanto, em segundo lugar, com isso não se deve duvidar da importância das tradições discursivas para a teoria da linguagem, mas justamente o contrário. Sua situação adequada do ponto de vista teórico-lingüístico é antes de mais nada o ponto de partida para a descrição do que elas realmente são, como elas devem ser definidas e quais serão as conseqüências para uma descrição histórico-lingüística que não se limite à evolução dum sistema lingüístico abstrato senão que dê conta, ao mesmo tempo, das tradições discursivas.

\section{Referências bibliográficas}

Aschenberg, Heidi (2003): "Diskurstraditionen - Orientierungen und Fragestellungen", in: Aschenberg/Wilhelm (Org.), p. 1-18.

Aschenberg, Heidi / Wilhelm, Raymund: Romanische Sprachgeschichte und Diskurstraditionen, Tübingen, Narr 2003.

Austin, John Langshaw, How to do things with words, Oxford, Oxford University Press, 1962.

Coseriu, Eugenio, Humanwissenschaften und Geschichte. Der Gesichtspunkt eines Linguisten, Det Norske Videnskaps-Akademi-Årbok, Oslo, 1978, 118-130.

1988. Sprachkompetenz. Elemente einer Theorie des Sprechens, Tübingen, Narr,

De la Higuera, Javier, Michel Foucault: La filosofía como crítica, Granada, Comares, 1999.

Foucault, Michel, L'archéologie du savoir, Paris, Gallimard, 1969.

L'ordre du discours, Paris, Gallimard, 1972.

Gadamer, Hans-Georg, Wahrheit und Methode. Grundzüge einer philosophischen Hermeneutik, 2. Aufl. Tübingen 1965.

Habermas, Jürgen, Vorbereitende Bemerkungen zu einer Theorie der kommunikativen Kompetenz, in: Jürgen Habermas/Niklas Luhmann, Theorie der Gesellschaft oder Sozialtechnologie, Frankfurt, Suhrkamp, 1971, 101-141.

Kabatek, Johannes, „La lingüística románica histórica: tradición e innovación en una disciplina viva“, La Corónica 31.2, 2003, 35-40.

"¿Cómo investigar las tradiciones discursivas medievales? El ejemplo de los textos jurídicos castellanos", in: Daniel Jacob u. Johannes Kabatek (Hrsg.): Lengua medieval y tradiciones discursivas en la Península Ibérica: descripción gramatical pragmática histórica - metodología, Frankfurt/Main-Madrid: Vervuert/Iberoamericana 2001 (Lingüística Iberoamericana, 12), S. 97-132.

Die Bolognesische Renaissance und der Ausbau romanischer Sprachen Juristische Texttraditionen und Sprachentwicklung in Südfrankreich und Spanien im 12. und 13. Jahrhundert, Tübingen: Niemeyer, 2004.

Koch, Peter, Diskurstraditionen: zu ihrem sprachtheoretischen Status und ihrer Dynamik, in: Barbara Frank/Thomas Haye/Doris Tophinke (edd.), Gattungen mittelalterlicher Schriftlichkeit, Tübingen, Narr, 1997, 43-79.

Koch, Peter/Oesterreicher, Wulf, Sprache der Nähe - Sprache der Distanz. Mündlichkeit und Schriftlichkeit im Spannungsfeld von Sprachtheorie und Sprachgeschichte, Romanistisches Jahrbuch 36 (1985), 15-43.

Tübingen, Niemeyer, 1990.

Gesprochene Sprache in der Romania: Französisch, Italienisch, Spanisch, 
Schriftlichkeit und Sprache, in: Hartmut Günther/Otto Ludwig (edd.), Schrift und Schriftlichkeit. Ein internationales Handbuch / Writing and its Use. An international Handbook, 2 Bde., Berlin/New York, Mouton de Gruyter, 1994-1996, 587-604. Raphael, Lutz, Geschichtswissenschaft im Zeitalter der Extreme. Theorien, Methoden, Tendenzen von 1900 bis zur Gegenwart, München, Beck, 2003.

Schlieben-Lange, Brigitte/Weydt, Harald [mit Beiträgen von Eugenio Coseriu und HansUlrich Gumbrecht], Streitgespräch zur Historizität von Sprechakten, Linguistische Berichte 60 (1979), 65-78.

Schlieben-Lange, Brigitte, Linguistische Pragmatik, Stuttgart, Kohlhammer, 1979.

Traditionen des Sprechens. Elemente einer pragmatischen Sprachgeschichtsschreibung, Stuttgart, Kohlhammer, 1983.

Alterität als sprachtheoretisches Konzept, Zeitschrift für Literaturwissenschaft und Linguistik 110 (Thema: Alterität, 1998), 41-57.

Voelker, P. (1886): „Die Bedeutungsentwickelung des Wortes Roman“, Zeitschrift für Romanische Philologie 10, 485-525.

Wilhelm, Raymund (2001): "Diskurstraditionen”, in: Martin Haspelmath/Ekkehard König/Wulf Oesterreicher/Wolfgang Raible (Org.) Language Typology and Language Universals. An International Handbook, I, Berlin/New York: de Gruyter, pp. 467-477.

(2003). "Von der Geschichte der Sprachen zur Geschichte der Diskurstraditionen. Für eine linguistische fundierte Kommunikationsgeschichte" in Aschenberg/Wilhelm (Org.), pp. 221-236. 